\title{
Structural Consequences of Calmodulin EF Hand
}

\section{Mutations}

Michael Piazza, Valentina Taiakina, Thorsten Dieckmann and J. Guy Guillemette ${ }^{1 *}$

From the Department of Chemistry, University of Waterloo, Waterloo, Ontario N2L 3G1,

Canada

Keywords: calcium, calmodulin $(\mathrm{CaM})$, nitric oxide synthase, electrostatics, protein structure

\footnotetext{
${ }^{1}$ This work was supported, in whole or in part, by the Natural Sciences and Engineering

Research Council of Canada (NSERC) via Grants 326911 (to T.D) and 183521 (to J.G.G)

* To whom correspondence should be addressed: Dept. of Chemistry, University of Waterloo, 200 University Ave. W, Waterloo, Ontario N2L 3G1 Canada. Tel. 519-888-4567 ext. 35954; Fax

519-746-0435; E-mail: jguillem@uwaterloo.ca; tdieckma@uwaterloo.ca
} 
Abbreviations: CaM, Calmodulin; iNOS, inducible nitric oxide synthase; CaM-iNOS complex, CaM-iNOS binding domain peptide in complex; HSQC, heteronuclear single-quantum coherence; PDB, Protein Data Bank; apoCaM, $\mathrm{Ca}^{2+}$ deplete $\mathrm{CaM} ; \mathrm{CaM}_{12}$, $\mathrm{CaM}$ protein defective in $\mathrm{Ca}^{2+}$ binding in the N-lobe $\mathrm{EF}$ hands with CaM D20A and D56A mutations; $\mathrm{CaM}_{34}, \mathrm{CaM}$ protein defective in $\mathrm{Ca}^{2+}$ binding in the $\mathrm{C}$-lobe $\mathrm{EF}$ hands with CaM D93A and D129A mutations; $\mathrm{CaM}_{1234}, \mathrm{CaM}$ protein defective in $\mathrm{Ca}^{2+}$ binding in all $4 \mathrm{EF}$ hands with CaM D20A, D56A, CaM D93A and D129A mutations; r.m.s.d., root-mean-square distance; APBS, Adaptive PoissonBoltzmann Solver; BMRB, Biological Magnetic Resonance Bank; SPR, surface plasmon resonance. 
ABSTRACT: Calmodulin $(\mathrm{CaM})$ is a cytosolic $\mathrm{Ca}^{2+}$-binding protein that serves as a control element for many enzymes. It consists of two globular domains, each containing two EF hand pairs capable of binding $\mathrm{Ca}^{2+}$, joined by a flexible central linker region. $\mathrm{CaM}$ is able to bind and activate its target proteins in the $\mathrm{Ca}^{2+}$-replete and $\mathrm{Ca}^{2+}$-deplete forms. To study the $\mathrm{Ca}^{2+}$ dependent/independent properties of binding and activation of target proteins by $\mathrm{CaM}, \mathrm{CaM}$ constructs with $\mathrm{Ca}^{2+}$ binding disrupting mutations of Asp to Ala at position one of each EF hand have been used. These CaM mutant proteins are deficient in binding $\mathrm{Ca}^{2+}$ in either the N-lobe $\mathrm{EF}$ hands $\left(\mathrm{CaM}_{12}\right)$, C-lobe $\mathrm{EF}$ hands $\left(\mathrm{CaM}_{34}\right)$, or all four $\mathrm{EF}$ hands $\left(\mathrm{CaM}_{1234}\right)$. To investigate potential structural changes these mutations may cause we performed detailed NMR studies of $\mathrm{CaM}_{12}, \mathrm{CaM}_{34}$, and $\mathrm{CaM}_{1234}$ including determining the solution structure of $\mathrm{CaM}_{1234}$. We then investigated if these $\mathrm{CaM}$ mutants affected the interaction of $\mathrm{CaM}$ with a target protein known to interact with apoCaM by determining the solution structure of $\mathrm{CaM}_{34}$ bound to the iNOS CaM binding domain peptide. The structures provide direct structural evidence of changes that are present in these $\mathrm{Ca}^{2+}$ deficient $\mathrm{CaM}$ mutants and shows these mutations increase the hydrophobic exposed surface and decrease the electronegative surface potential throughout each lobe of CaM. These $\mathrm{Ca}^{2+}$ deficient $\mathrm{CaM}$ mutants may not be a true representation of apoCaM and may not allow for native-like interactions of apoCaM with its target proteins. 


\section{INTRODUCTION}

Calmodulin $(\mathrm{CaM})$ is a small cytosolic $\mathrm{Ca}^{2+}$-binding protein able to bind and regulate hundreds of different intracellular proteins. ${ }^{1}$ CaM's structure consists of two globular domains, each containing two EF hand pairs capable of binding to $\mathrm{Ca}^{2+}$. These two domains are joined by a flexible central linker region that allows it to adapt its conformation to optimally associate with its intracellular targets. ${ }^{2}$ The EF hand consists of a helix-loop-helix motif, consisting of a 12 residue long $\mathrm{Ca}^{2+}$ binding loop rich in aspartates and glutamates. ${ }^{3}$ In the absence of $\mathrm{Ca}^{2+}$ the helix-loop-helix motif of the EF hands are in a "closed" conformation, with their hydrophobic residues packed into their central core and their charged, hydrophilic residues solvent-exposed. ${ }^{4,5}$ When a $\mathrm{Ca}^{2+}$ ion binds, the helices rearrange into a more "open" conformation, exposing hydrophobic patches in each domain that allow $\mathrm{CaM}$ to bind to its target proteins. ${ }^{3,4,6} \mathrm{CaM}$ is able to bind to its target proteins in the $\mathrm{Ca}^{2+}$-replete and $\mathrm{Ca}^{2+}$-deplete forms. ${ }^{7-9}$ There is considerable interest in obtaining a better understanding of the structural basis for CaM's ability to bind and recognize its numerous target proteins.

Mutant CaM proteins are commonly used to investigate the $\mathrm{Ca}^{2+}$-dependent and independent properties of $\mathrm{CaM}$ binding and activation of target proteins. These include mutation of the Asp residue to Ala at position 1 to inactivate $\mathrm{Ca}^{2+}$ binding in the $\mathrm{EF}$ hand. ${ }^{10-13}$ These $\mathrm{CaM}$ mutants are unable to bind $\mathrm{Ca}^{2+}$ in either the N-terminal lobe $\mathrm{EF}$ hands $\left(\mathrm{CaM}_{12}\right.$; $\mathrm{CaM}$ D20A and D56A mutations), the C-terminal lobe $\mathrm{EF}$ hands $\left(\mathrm{CaM}_{34}\right.$; $\mathrm{CaM} \mathrm{D} 93 \mathrm{~A}$ and D129A), or all four $\mathrm{Ca}^{2+}{ }_{-}$ binding $\mathrm{EF}$ hands $\left(\mathrm{CaM}_{1234}\right.$; mutations at D20A, D56A, D93A and D129A inclusive). Many studies have expressed these Asp to Ala CaM mutants in cells to determine the relative functional contribution of $\mathrm{Ca}^{2+}$ binding to each lobe of $\mathrm{CaM}^{14-34}$ The overexpression of $\mathrm{CaM}$ proteins carrying EF hand mutations in cell culture studies of calcium channels is a commonly 
used method for investigating native molecular mechanisms of $\mathrm{CaM}$ and the functional contribution of $\mathrm{Ca}^{2+} \cdot{ }^{15-20,30-33}$ Meaningful interpretation of these investigations should account for differences in the structural integrity of the native apoCaM and the CaM mutant proteins carrying defective $\mathrm{Ca}^{2+}$-binding EF-hands.

The mutation of D93 and D129 to Ala effectively prevents $\mathrm{Ca}^{2+}$ binding to EF hands III and IV, however, it has been shown these mutations may cause structural perturbations in the Cdomain. ${ }^{13}$ This suggests that the $\mathrm{Ca}^{2+}$-inactivating mutations may cause $\mathrm{CaM}$ to adopt a nonnative apo structure. To investigate these potential structural changes we performed detailed NMR structural studies of $\mathrm{CaM}_{12}, \mathrm{CaM}_{34}$, and $\mathrm{CaM}_{1234}$ in the absence and presence of $\mathrm{Ca}^{2+}$. The solution structure of $\mathrm{CaM}_{1234}$ was determined to examine the effects of these mutations compared to the solution structure of apoCaM. This structure shows that the Asp to Ala mutation cause slight structural and electrostatic surface changes throughout each EF hand.

To further our investigation of these CaM mutants, NMR studies were performed on their association with the CaM binding domain from inducible nitric oxide synthase (iNOS). The iNOS CaM binding domain interacts with the $\mathrm{Ca}^{2+}$-replete and $\mathrm{Ca}^{2+}$-deplete forms of $\mathrm{CaM}^{35-37}$ The iNOS enzyme catalyzes the production of nitric oxide $(\cdot \mathrm{NO})$ that acts as a secondary interand intracellular messenger involved in many physiological processes. ${ }^{38}$ It consists of a dimerized oxygenase domain, flanked by two separated reductase domains, that exist in an equilibrium of conformations alternating between FAD-FMN electron transfer (input state) and FMN-heme electron transfer (output state). ${ }^{39-41}$ CaM activates NOS through the precise positioning of the FMN subdomain necessary for the transferring of electrons to the oxygenase domain. ${ }^{41,42}$ The iNOS enzyme binds to $\mathrm{CaM}$ at basal levels of $\mathrm{Ca}^{2+}$ and is transcriptionally regulated in vivo by cytokines. ${ }^{43,44}$ A previous study of iNOS activity using $\mathrm{CaM}_{12}$ and $\mathrm{CaM}_{34}$ to 
determine if the $\mathrm{Ca}^{2+}$-free $\mathrm{N}$ - or C-lobe of $\mathrm{CaM}$ was responsible for the $\mathrm{Ca}^{2+}$-independent association of CaM to iNOS showed that iNOS was active for both in the presence of $\mathrm{Ca}^{2+}$, whereas in the presence of EDTA $\mathrm{CaM}_{34}$ showed a substantial decrease in iNOS activity. ${ }^{24} \mathrm{We}$ thus determined the solution structure of $\mathrm{CaM}_{34}$ bound to the iNOS CaM binding domain peptide and compared that to the previously determined holoCaM-iNOS complex to provide further insight into this decrease in activity. This structure, along with that of $\mathrm{CaM}_{1234}$ showed that the Asp to Ala mutations are associated with an increase in surface hydrophobicity and a decrease in the electronegative surface potential throughout each lobe of $\mathrm{CaM}$. These structures show these mutations may not be a true representation of apoCaM and may not allow for native-like interactions of apoCaM with its target proteins.

\section{EXPERIMENTAL PROCEDURES}

Sample Preparation for NMR Investigation. $\mathrm{CaM}_{12}, \mathrm{CaM}_{34}$ and $\mathrm{CaM}_{1234}$ for $\mathrm{NMR}$ experiments were expressed in E. coli in $1 \mathrm{~L}$ of $\mathrm{M} 9$ media $\left(11.03 \mathrm{~g} / \mathrm{L} \mathrm{Na}_{2} \mathrm{HPO}_{4} \cdot 7 \mathrm{H}_{2} \mathrm{O}, 3.0 \mathrm{~g} / \mathrm{L}\right.$ $\mathrm{KH}_{2} \mathrm{PO}_{4}, 0.5 \mathrm{~g} / \mathrm{L} \mathrm{NaCl}, 2 \mathrm{mM} \mathrm{MgSO}{ }_{4}, 0.1 \mathrm{mM} \mathrm{CaCl}_{2}, 3 \mu \mathrm{M}\left(\mathrm{NH}_{4}\right)_{6}\left(\mathrm{MO}_{7}\right)_{24}, 400 \mu \mathrm{M} \mathrm{H}_{3} \mathrm{BO}_{3}, 30$ $\mu \mathrm{M} \mathrm{CoCl} 2,10 \mu \mathrm{M} \mathrm{CuSO}_{4}, 80 \mu \mathrm{M} \mathrm{MnCl} 2 \cdot 4 \mathrm{H}_{2} \mathrm{O}, 10 \mu \mathrm{M} \mathrm{ZnCl} 2,10 \mathrm{mM} \mathrm{FeSO}{ }_{4}, 100 \mu \mathrm{g} / \mathrm{mL}$ kanamycin) containing $2 \mathrm{~g} / \mathrm{L}{ }^{13} \mathrm{C}$-glucose and $1 \mathrm{~g} / \mathrm{L}{ }^{15} \mathrm{NH}_{4} \mathrm{Cl} .{ }^{13} \mathrm{C}^{15}{ }^{15} \mathrm{CaM}$ was purified as previously described. ${ }^{24}$ Purity of the mutant CaM protein (148 residues) was confirmed by ESIMS and was judged to be $>95 \%$ by SDS-PAGE. The human iNOS peptide (RREIPLKVLVKAVLFACMLMRK, 22 residues corresponding to residues 510-531 from the full length iNOS protein) was synthesized and purchased from CanPeptide Inc. (Montreal, Canada). The iNOS peptide used for SPR was synthesized with biotin attached to the N-terminus to allow for binding to the sensor chip functionalized with an immobilized coating of streptavidin. 
The $\mathrm{Ca}^{2+}-\mathrm{CaM}_{12}, \mathrm{Ca}^{2+}-\mathrm{CaM}_{34}$ and $\mathrm{CaM}_{34}$-iNOS samples were prepared for NMR experiments via a buffer exchange into $\mathrm{NMR}$ solution $(100 \mathrm{mM} \mathrm{KCl}, 10 \mathrm{mM} \mathrm{CaCl} 2,0.2 \mathrm{mM} \mathrm{NaN}, 90 \%$ $\mathrm{H}_{2} \mathrm{O} / 10 \%{ }^{2} \mathrm{H}_{2} \mathrm{O}$ ) at pH 6.0 using a YM10 centrifugal filter device (Millipore Corp., Billerica, USA). The apoCaM 12 , apoCaM 34 and $\mathrm{CaM}_{1234}$ samples were prepared for NMR experiments via a buffer exchange into NMR solution (100 mM KCl, $0.2 \mathrm{mM}$ EDTA, $0.2 \mathrm{mM} \mathrm{NaN}$, 90\% $\mathrm{H}_{2} \mathrm{O} / 10 \%{ }^{2} \mathrm{H}_{2} \mathrm{O}$ ) at pH 6.0 using a YM10 centrifugal filter device (Millipore Corp., Billerica, USA). All NMR samples contained at least $1 \mathrm{mM} \mathrm{CaM}$ in a total volume of $500 \mu \mathrm{L}$. The samples were transferred into $5 \mathrm{~mm}$ NMR sample tubes and stored at $4^{\circ} \mathrm{C}$ until required for $\mathrm{NMR}$ experiments. NMR experiments on the $\mathrm{CaM}_{34}$-iNOS complex were conducted on samples titrated with iNOS peptide to saturation in a 1:1 CaM:peptide ratio. After each addition a ${ }^{1} \mathrm{H}-{ }^{15} \mathrm{~N}$ heteronuclear single-quantum coherence (HSQC) spectrum was acquired to monitor complex formation.

NMR Spectroscopy and Data Analysis. NMR spectra were recorded at $25^{\circ} \mathrm{C}$ on Bruker 600 MHz DRX spectrometers equipped with XYZ-gradients triple-resonance probes (Bruker, Billerica, MA, USA). Spectra were analyzed using the program CARA. ${ }^{45}$ Specific assignments of the backbone resonances of the $\mathrm{CaM}_{12}$-iNOS and $\mathrm{CaM}_{34}$-iNOS complexes and $\mathrm{CaM}_{1234}$ alone were achieved using a combination of three-dimensional triple-resonance experiments, including HNCA and $\mathrm{CBCA}(\mathrm{CO}) \mathrm{NH}$ and the previously obtained amide chemical shifts of $\mathrm{Ca}^{2+}$ saturated $\mathrm{CaM}$ with the iNOS peptide as reference. ${ }^{46-49}$ Side chain resonances for the $\mathrm{CaM}_{34-\mathrm{iNOS}}$ complex and $\mathrm{CaM}_{1234}$ alone were assigned using the TOCSY-type HC(C)H-TOCSY and (H)CCH- TOCSY experiments. ${ }^{50}$ Specific assignments of the iNOS peptide in the $\mathrm{CaM}_{34}$-iNOS complex were obtained from ${ }^{15} \mathrm{~N}$-double-filtered NOESY experiments. ${ }^{51}$ 
Structure Calculation of the $\mathrm{CaM}_{34}$-iNOS Peptide Complex and $\mathrm{CaM}_{1234}$ Alone. Distance constraints for $\mathrm{CaM}_{1234}$ were obtained from ${ }^{15} \mathrm{~N}$ NOESY-HSQC, ${ }^{13} \mathrm{C}_{\text {ali }}$ NOESY- HSQC and ${ }^{13} \mathrm{C}_{\text {aro }}$ NOESY- HSQC spectra. Distance constraints for the $\mathrm{CaM}_{34-\mathrm{iNOS}}$ complex were obtained from ${ }^{15} \mathrm{~N}$ NOESY-HSQC and ${ }^{13} \mathrm{C}$ NOESY- HSQC, and ${ }^{15} \mathrm{~N}$ - double-filtered NOESY spectra acquired on samples containing ${ }^{13} \mathrm{C}_{-}{ }^{15} \mathrm{~N}-\mathrm{CaM}_{34}$ and unlabeled peptide ${ }^{51-53}$ In addition, dihedral angle restraints were derived from chemical shift analysis with TALOS+. The structure calculations of $\mathrm{CaM}_{34}$-iNOS peptide complex and of $\mathrm{CaM}_{1234}$ alone were performed using CNSsolve version 1.2 and initiated with an extended conformation file. ${ }^{54}$ The calculation was run through several iterations of a standard simulated annealing protocol to minimize the energies and the final 20 lowest energy structures were selected.

Accession Numbers. The coordinates and NMR parameters have been deposited in the Protein Data Bank (PDB) and the BioMagResBank (BMRB) and have been assigned PDB entry 5TP5, and BMRB accession number 30195 for $\mathrm{CaM}_{1234}$ and PDB entry 5TP6, and BMRB 30196 accession number for the $\mathrm{CaM}_{34}$-iNOS complex.

Electrostatics and Hydrophobicity Calculations. Electrostatic potentials of the CaM-iNOS and $\mathrm{CaM}_{34}$-iNOS structures were calculated using the APBS (Adaptive Poisson-Boltzmann Solver) and PDB2PQR software packages. ${ }^{55-57}$ The hydrophobicity surface was calculated using the kdHydrophobicity attribute function of UCSF Chimera version 1.5.3 (build 33475) ${ }^{58}$ assigning values according to the amino acid hydrophobicity scale of Kyte and Doolittle. ${ }^{59}$ The electrostatic potential and hydrophobicity surfaces were viewed in Chimera.

Surface Plasmon Resonance. SPR experiments were performed with an openSPR instrument (Nicoya Lifesciences, Waterloo, Canada) at $25^{\circ} \mathrm{C}$ with a $100 \mu \mathrm{L}$ loading loop and a constant flow rate of $50 \mu \mathrm{L} / \mathrm{min}$. The iNOS peptide with a biotin moiety added to the $\mathrm{N}$-terminus was bound to 
a sensor chip functionalized with an immobilized coating of streptavidin. Binding of CaM was tested in either saturating $\mathrm{Ca}^{2+}$ buffer (30 mM MOPS, $100 \mathrm{mM} \mathrm{KCl}$, $\mathrm{pH} 7.2$ and $0.1 \mathrm{mM} \mathrm{CaCl}_{2}$ ) or $17 \mathrm{nM}$ free $\mathrm{Ca}^{2+}$ buffer (30 mM MOPS, $100 \mathrm{mM} \mathrm{KCl,} \mathrm{pH}$ 7.2, and combination of $10 \mathrm{mM}$ EGTA and $10 \mathrm{mM}$ CaEGTA to obtain a final $17 \mathrm{nM}$ concentration of free $\left.\mathrm{Ca}^{2+}\right)$. CaM was injected over the bound biotin-iNOS peptide in concentrations from 10 to $300 \mathrm{nM}$ for 2 minutes to allow association. $\mathrm{CaM}$ free saturating $\mathrm{Ca}^{2+}$ or $17 \mathrm{nM}$ free $\mathrm{Ca}^{2+}$ buffer was passed over the sensor for 12 minutes to allow dissociation. Following each CaM injection, $10 \mathrm{mM} \mathrm{HCl}$ was injected to completely dissociate the complex and regenerate the unbound iNOS peptide. Analysis of the data was made using Trace Drawer software (Ridgeview Instruments $A B$ ) as recommended by the manufacturer. Kinetic parameters were calculated using global analysis, fitting the data to a simple $1: 1$ model $(\mathrm{A}+\mathrm{B} \leftrightarrow \mathrm{AB})$ for $\mathrm{CaM}-, \mathrm{CaM}_{34^{-}}$and $\mathrm{CaM}_{1234^{-}}$ interactions with the iNOS peptide at saturated $\mathrm{Ca}^{2+}$.

\section{RESULTS}

\section{NMR Structural Studies of $\mathrm{CaM}_{12}$ and $\mathrm{CaM}_{34}$ Indicate Possible Structural}

Perturbations Caused by the Mutations. ${ }^{1} \mathrm{H}^{-15} \mathrm{~N}$ HSQC experiments were performed to determine if significant structural changes occur due to mutations in the four EF hands of CaM. The complete backbone assignment of $\mathrm{CaM}_{1234}$ and $\mathrm{CaM}_{12}$ and $\mathrm{CaM}_{34}$ and in the absence and presence of $\mathrm{Ca}^{2+}$ was completed. These assignments were used to probe potential structural changes caused by the mutations through an ${ }^{1} \mathrm{H}-{ }^{15} \mathrm{~N}$ HSQC comparison with apo and holoCaM. Comparing the $\mathrm{CaM}_{1234}$ spectrum to that of apoCaM${ }^{5}$, chemical shift changes induced by the 4 EF hand mutations appear for the amides throughout all 4 of the $\mathrm{Ca}^{2+}$-binding EF hands (Fig. 1A). The chemical shift differences for $\mathrm{CaM}_{12}$ and $\mathrm{CaM}_{34}$ were calculated to determine if the chemical shift differences observed for $\mathrm{CaM}_{1234}$ are a sum of the individual differences observed 
for the mutated $\mathrm{EF}$ hands between apoCaM and $\mathrm{CaM}_{12}$, and apoCaM and $\mathrm{CaM}_{34}$. Fig. $1 \mathrm{~B}$ and $\mathrm{C}$ shows the chemical shift differences calculated from the ${ }^{1} \mathrm{H}^{-15} \mathrm{~N}$ HSQC spectra overlay of apoCaM, apoCaM 12 and apoCaM 34 (Supplemental Fig. S1A). Cross-peaks for amides in the Clobe of apoCaM $\mathrm{M}_{12}$ overlap with those of apoCaM, however, amides in the N-lobe, specifically the residues in the $\mathrm{Ca}^{2+}$ binding loops of the EF hands, do not overlap with those of apoCaM. Conversely, cross-peaks for amides in the N-lobe of apoCaM 34 overlap with those of apoCaM, however, amides in the $\mathrm{C}$-lobe, specifically the residues in the $\mathrm{Ca}^{2+}$ binding loops of the $\mathrm{EF}$ hands, do not overlap with those of apoCaM. This data shows that the Asp to Ala mutations not only knock out $\mathrm{Ca}^{2+}$ binding to the $\mathrm{EF}$ hands but also cause potential structural changes.

Fig. 1D and E show the chemical shift differences calculated from the ${ }^{1} \mathrm{H}^{15} \mathrm{~N}$ HSQC spectra overlay of holoCaM, $\mathrm{Ca}^{2+}-\mathrm{CaM}_{12}$ and $\mathrm{Ca}^{2+}-\mathrm{CaM}_{34}$ (Supplemental Fig. 1B). As observed for apoCaM 12 , cross-peaks for the majority of amides in the $\mathrm{C}$-lobe of $\mathrm{Ca}^{2+}-\mathrm{CaM}_{12}$ overlap with those of holoCaM, and amides in the N-lobe, specifically the residues in the $\mathrm{Ca}^{2+}$ binding loops of the EF hands, do not overlap. However, unlike apoCaM 12 there are a few residues in the $\mathrm{C}$ lobe that are calculated to have a chemical shift difference greater than $0.1 \mathrm{ppm}$.

Also as observed for apoCaM 34 , cross-peaks for amides in the N-lobe of $\mathrm{Ca}^{2+}-\mathrm{CaM}_{34}$ overlap with those of holoCaM, and amides in the $\mathrm{C}$-lobe, specifically the residues in the $\mathrm{Ca}^{2+}$ binding loops of the EF hands, do not. Like $\mathrm{Ca}^{2+}-\mathrm{CaM}_{12}$, residues in the opposite lobe appear to be affected by the mutations also. In the $\mathrm{Ca}^{2+}-\mathrm{CaM}_{34}$ case there are quite a few $\mathrm{N}$-lobe residues, spread throughout the whole domain, that are calculated to have a chemical shift difference greater than $0.1 \mathrm{ppm}$. This data suggests that the Asp to Ala mutations not only knock out $\mathrm{Ca}^{2+}$ binding to the EF hands where the mutations occur, but also cause potential structural changes in the opposite lobe. Some of the residues that experience the greatest changes are the hydrophobic 
residues Phe12, Phe16, Leu18, Phe19 and Met36 in EF hand I and the hydrophobic residues, Val55, Ala57, Ile63 and Phe65 in the $\mathrm{Ca}^{2+}$ binding loop of EF hand II. These structural changes appear to not only be located to the specific EF hands that contain the mutation but also to residues of the opposite domain, especially in the case of $\mathrm{Ca}^{2+}-\mathrm{CaM}_{34}$.

Solution Structure of $\mathbf{C a M}_{1234}$. To probe these potential conformational changes further the structure determination of apoCaM $\mathrm{M}_{1234}$ was undertaken. The ${ }^{1} \mathrm{H}_{-}{ }^{15} \mathrm{~N}$ HSQC spectrum of $\mathrm{CaM}_{1234}$ exhibits good resolution and well dispersed signals, indicating a uniform and folded protein structure (Supplemental Fig. 2). The three-dimensional solution structure of $\mathrm{CaM}_{1234}$ was determined using multidimensional heteronuclear NMR spectroscopy. The structure of the complex is based on a large number of experimental constraints and is well-defined. Structure and input data statistics are summarized in Table 1. The family of 20 lowest energy structures is shown in Fig. 2A and B. Due to the high degree of flexibility of CaM's central linker it is not possible to superimpose both the $\mathrm{C}$ and N-lobes at the same time. Superimposing the ensemble of structures with respect to the N-lobe backbone atoms shows a fairly well overlapped N-lobe of $\mathrm{CaM}_{1234}$, with an r.m.s.d. of 0.4 for the backbone atoms and $0.9 \AA$ for heavy atoms. In contrast, superimposing the ensemble with respect to the C-lobe backbone atoms shows a poorer overlap for $\mathrm{CaM}_{1234}$, as shown by an r.m.s.d. of 0.8 for the backbone atoms and $1.3 \AA$ for heavy atoms. This indicates the N-lobe has a more stable structure than the $\mathrm{C}$-lobe, which has previously been reported to have a well-defined hydrophobic core, compared to a C-lobe with a less defined hydrophobic core in the apoCaM structures. ${ }^{4,5}$

Fig. 2C shows the structure consists of 8 helices, and has the characteristic helix-loop-helix conformation for each EF hand, as observed in other apo and $\mathrm{Ca}^{2+}$-replete structures of $\mathrm{CaM}{ }^{4,5,60}$ When the ensemble of structures are superimposed with respect to a specific lobe, the linker 
region is shown to be very flexible, as evidenced by the opposite lobe being distributed in different conformations relative to the superimposed lobe. This is also supported by the lack of long range NOEs observed for the linker residues or between the two lobes.

$\mathrm{CaM}_{1234}$ Structure Comparison to ApoCaM. The $\mathrm{CaM}_{1234}$ structure was compared to the previously determined solution structure of apoCaM (PDB entry $1 \mathrm{CFC})^{5}$ to determine any structural changes incurred by the Asp to Ala mutations in position 1 of the four EF hands. Due to the highly flexible linker region described above, the two lobes of $\mathrm{CaM}$ of the two structures were compared separately (Fig. 3). When the two structures were superimposed with respect to CaM's N-lobe backbone atoms (residues 4-70) a r.m.s.d. value of $2.9 \AA$ A was found. Fig. 3A and B shows the superposition of the N-lobe of $\mathrm{CaM}_{1234}$ and apoCaM. Helix A and the loop region connecting the two EF hands overlay quite well in both structures, whereas helix B is shifted down compared to apoCaM and the $\mathrm{Ca}^{2+}$-binding loop of $\mathrm{EF}$ hand $\mathrm{I}$ is tilted away from the $\mathrm{Ca}^{2+}-$ binding loop of EF hand II.

When the two structures are superimposed with respect to the C-lobe backbone atoms (residues 84-148) a r.m.s.d. value of $2.6 \AA$ was found. Fig. 3C and D shows the superposition of the C-lobe of $\mathrm{CaM}_{1234}$ and apoCaM, which displays more subtle changes and less drastic conformational changes compared to the N-lobe. The largest differences seen are a bulge of the $\mathrm{Ca}^{2+}$-binding loop of EF hand III at the Asp93 to Ala mutation site and the tilting inwards of helix E.

Effect of EF Hand Mutations on the Electrostatic and Hydrophobicity Surface Maps. The electrostatic surface potential of apoCaM and $\mathrm{CaM}_{1234}$ were calculated using the APBS (Adaptive Poisson-Boltzmann Solver) and PDB2PQR software packages and mapped onto the surfaces of the apoCaM and $\mathrm{CaM}_{1234}$ solution structures (Fig. 4A, B and D, E, respectively). The 
negative surface charge observed throughout apoCaM has been drastically reduced throughout all $4 \mathrm{EF}$ hands of the $\mathrm{CaM}_{1234}$ structure. The hydrophobicity surface was also calculated, using Chimera, and mapped onto the surfaces of apoCaM and $\mathrm{CaM}_{1234}$ (Fig. 4C and F, respectively). The mutations have reduced the hydrophilic surface area and increased the hydrophobic surface area throughout the two lobes of the $\mathrm{CaM}_{1234}$ structure.

NMR Structure of $\mathrm{CaM}_{34}$ and the iNOS CaM Binding Domain Peptide Complex. -We next determined the solution structure of $\mathrm{CaM}_{34}$ bound to a peptide of a target protein, iNOS, to investigate if these $\mathrm{CaM}$ mutants affected the interaction of $\mathrm{CaM}$ with target proteins known to interact with apoCaM. Overall, the ${ }^{1} \mathrm{H}-{ }^{15} \mathrm{~N}$ HSQC spectrum of $\mathrm{CaM}_{34}$ in complex with the peptide of the iNOS CaM-binding domain exhibits good resolution and well dispersed signals, indicating a uniform and folded protein structure (Supplemental Fig. S3A). Upon comparison with the ${ }^{1} \mathrm{H}-{ }^{15} \mathrm{~N}$ HSQC spectrum of the holoCaM complex chemical shift changes induced by the $\mathrm{C}$-lobe $\mathrm{EF}$ hand mutations appear predominately for the amides coordinating the $\mathrm{Ca}^{2+}$ ion in EF hands III and IV, with the greatest differences occurring for the amides in the center of the $\mathrm{Ca}^{2+}$-binding loop (Supplemental Fig. S3B). The majority of the amide resonances of the N-lobe show little chemical shift differences, suggesting both complexes have a similar structure of the N-lobe bound to iNOS, however, a few meaningful differences are observed.

The three-dimensional solution structure of $\mathrm{CaM}_{34}$-iNOS complex was determined using multidimensional heteronuclear NMR spectroscopy. The structure of the complex is based on a large number of experimental constraints and is well-defined. Residues 1- 12 at the N-terminus of the iNOS peptide (corresponding to residues 503-514 of full length iNOS) show a lack of structure because they could not be unambiguously assigned and were omitted from the structure 
calculation. The root-mean-square distance (r.m.s.d.) for ordered residues is $1.0 \AA$ for the backbone atoms and $1.4 \AA$ for all non-hydrogen atoms (Table 2).

The family of 20 lowest energy structures is shown in Fig. 5A. This ensemble of structures shows a more closely overlapped $\mathrm{N}$-lobe of $\mathrm{CaM}_{34}$ compared to a $\mathrm{C}$-lobe that displays more fluctuation in the ensemble of structures. This can be further shown by looking at the r.m.s.d. values for each individual lobe of $\mathrm{CaM}_{34}$ in complex with the iNOS peptide. The r.m.s.d. for the C-lobe residues is $1.0 \AA$ for the backbone atoms and $1.7 \AA$ for all non-hydrogen atoms, whereas it is $0.7 \AA$ for the backbone atoms and $1.2 \AA$ for all non-hydrogen atoms of the N-lobe. The $\mathrm{CaM}_{34}$-iNOS complex has a $\mathrm{Ca}^{2+}$-replete $\mathrm{N}$-lobe and a $\mathrm{Ca}^{2+}$-deplete $\mathrm{C}$-lobe bound to the iNOS peptide as shown in Fig. 5B. This structure shows CaM is still able to bind to iNOS with both lobes, even when the $\mathrm{C}$-lobe of $\mathrm{CaM}$ is $\mathrm{Ca}^{2+}$-deplete due to the Asp to Ala mutations.

\section{$\mathrm{CaM}_{34}$-iNOS Structure Comparison to the holoCaM-iNOS Complex and ApoCaM. When} the $\mathrm{CaM}_{34}$-iNOS complex structure is compared to the previously determined solution structure of the holoCaM-iNOS complex (PDB entry 2LL6) ${ }^{46}$, the N-lobes of $\mathrm{CaM}$ and peptide orientation are quite similar, however the $\mathrm{Ca}^{2+}$ binding loops of EF hands III and IV of the Clobe of $\mathrm{CaM}$ are structurally different (Fig. 6A-D). When the two structures are aligned with respect to $\mathrm{CaM}_{34}$-iNOS's backbone atoms a r.m.s.d. value of $4.2 \AA$ for the backbone atoms of CaM-iNOS was found. When the two structures are aligned with respect to CaM's N-lobe backbone atoms a r.m.s.d. value of $2.5 \AA$ was found, whereas, an r.m.s.d. value of 3.2 with respect to the C-lobe backbone atoms was found. The N-lobes of CaM and the iNOS peptide of each structure superimpose quite well on each other, whereas the $\mathrm{Ca}^{2+}$ binding loops of $\mathrm{EF}$ hands

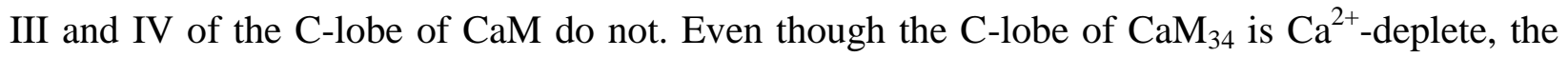
four $\alpha$-helices of the two EF hand loops still bind to the iNOS peptide in a similar fashion as in 
the holoCaM-iNOS complex. This is evident from the solution structure and also from the NOESY spectra. The inter-residue NOEs observed for the residues of the $\alpha$-helices of $\mathrm{CaM}_{34}$ 's C-lobe are very similar to those observed for the same residues in the holoCaM-iNOS complex. The $\mathrm{Ca}^{2+}$ binding loops of EF hands III and IV are more compact in the holoCaM-iNOS complex compared to the $\mathrm{CaM}_{34}$-iNOS complex and the loop region connecting EF hands III and IV is closer to the peptide in the $\mathrm{CaM}_{34}$-iNOS complex. The loop region connecting EF hands I and II and helix B are also shifted closer to the iNOS peptide.

When the $\mathrm{CaM}_{34}$-iNOS complex structure is compared to the previously determined apoCaM structure (PDB entry $1 \mathrm{CFC})^{5}$, there is structural similarity of the $\mathrm{Ca}^{2+}$ binding loop of EF hand III of the C-lobes of CaM (Fig. 6E and F). When the two structures are aligned with respect to CaM's EF hand III Ca ${ }^{2+}$-binding loop backbone atoms (residues 93-104) a r.m.s.d. value of $1.1 \AA$ was found. When the two structures are aligned with respect to CaM's C-lobe backbone atoms (residues 93-140) a r.m.s.d. value of $3.5 \AA$ was found. The structure and r.m.s.d. values suggest the $\mathrm{EF}$ hands of the $\mathrm{C}$-lobe adopt a similar $\mathrm{Ca}^{2+}$-deplete conformation for the $\mathrm{Ca}^{2+}$-binding loop, however the overall conformation of the helix-loop-helix motif is similar to the "open" conformation observed in the $\mathrm{Ca}^{2+}$-replete form (Fig. 6F).

\section{Effect of EF Hands 3 and 4 Mutations on the Electrostatic and Hydrophobicity Surface}

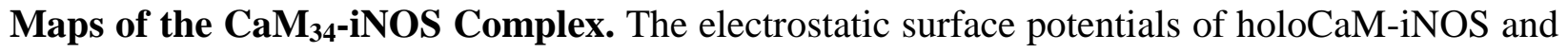
$\mathrm{CaM}_{34}$-iNOS were calculated and mapped onto their respective surfaces (Fig. 7A and B). As was observed for $\mathrm{CaM}_{1234}$, the EF hand III and IV mutations cause the C-lobe of $\mathrm{CaM}_{34}$ to have a less electronegative surface than that of holoCaM-iNOS. Overall the electrostatic surface of the Nlobe for both the holoCaM-iNOS and the $\mathrm{CaM}_{34}$-iNOS structures are quite similar (Supplemental Fig. 4). The hydrophobicity surface was mapped onto the surfaces of holoCaM-iNOS and 
$\mathrm{CaM}_{34-\mathrm{iNOS}}$ (Fig. 7C and D, respectively) and a slight increase of hydrophobic surface area can be observed near the mutation sites in the $\mathrm{CaM}_{34}$-iNOS structure.

Surface Plasmon Resonance of CaM, $\mathrm{CaM}_{1234}$ and $\mathrm{CaM}_{34}$ with iNOS. The interaction of the iNOS peptide with $\mathrm{CaM}, \mathrm{CaM}_{1234}$ and $\mathrm{CaM}_{34}$ was further analyzed using SPR. SPR analysis allows us to determine the binding kinetics of a protein to a peptide with the advantage of using a label-free system. The kinetics of this binding interaction, including the binding affinity, association and dissociation rates, was determined by the injection of different concentrations of CaM over a surface with an immobilized iNOS peptide.

Sensorgrams at various CaM concentrations (10 to $300 \mathrm{nM}$ ) were obtained at a saturating $\mathrm{Ca}^{2+}$ concentration of $1 \mathrm{mM}$ with the iNOS peptide (Supplementary Fig. S5). The sensorgrams consisted of three phases: an association phase, injection of buffer with CaM; a dissociation phase, flushing of the flow cell with CaM-free buffer; and a regeneration phase, injection of 10 $\mathrm{mM} \mathrm{HCl}$ for complete dissociation of the complex. Sensorgrams were analyzed by a simple 1:1 ( $\mathrm{A}+\mathrm{B} \leftrightarrow \mathrm{AB}$, where $\mathrm{A}$ is $\mathrm{CaM}$ and $\mathrm{B}$ is the immobilized iNOS peptide) fitting model using the Tracedrawer software (Ridgeview Instruments AB) (Table 3).

We determined the association rate, $\mathrm{k}_{\mathrm{a}}$, to be $27.5( \pm 0.01) \times 10^{4} \mathrm{M}^{-1} \mathrm{~s}^{-1}$ and the dissociation rate, $\mathrm{k}_{\mathrm{d}}$, to be $3.9( \pm 0.02) \times 10^{-4} \mathrm{~s}^{-1}$, giving a dissociation constant, $\mathrm{K}_{\mathrm{D}}$, of $1.4( \pm 0.01) \times 10^{-9} \mathrm{M}$ (Table 3) for $\mathrm{CaM}$ at saturating $\mathrm{Ca}^{2+}$, which is in good agreement with previously reported values that range from $<0.1-3.3 \times 10^{-9} \mathrm{M} .^{61-65}$ To mimic the basal $\mathrm{Ca}^{2+}$ normally found in the cell SPR experiments were performed at $17 \mathrm{nM}$ free $\mathrm{Ca}^{2+}$ concentration since previous structural studies have shown little change in overall CaM structure when bound to iNOS under these conditions compared to saturated $\mathrm{Ca}^{2+}$ concentrations. ${ }^{66}$ Sensorgrams were then obtained at the $17 \mathrm{nM}$ free $\mathrm{Ca}^{2+}$ concentration to evaluate the binding kinetics of $\mathrm{CaM}$ with the iNOS peptide. 
This yielded a $\mathrm{k}_{\mathrm{a}}$ of $20.5( \pm 0.02) \times 10^{4} \mathrm{M}^{-1} \mathrm{~s}^{-1}, \mathrm{k}_{\mathrm{d}}$ of $14.5( \pm 0.2) \times 10^{-4} \mathrm{~s}^{-1}$ and an apparent $\mathrm{K}_{\mathrm{D}}$ of $7.1( \pm 1.0) \times 10^{-9} \mathrm{M}$. To evaluate the binding kinetics of the CaM mutants investigated by NMR to the iNOS peptide we performed SPR experiments at saturating $\mathrm{Ca}^{2+}$. The binding of $\mathrm{CaM}_{1234}$ to the immobilized iNOS peptide resulted in a $\mathrm{K}_{\mathrm{D}}$ of $2.9( \pm 0.1) \times 10^{-9} \mathrm{M}$ with both slower on and off rates, whereas $\mathrm{CaM}_{34}$ binding to iNOS had faster on and off rates with a $\mathrm{K}_{\mathrm{D}}$ of $1.9( \pm 0.1)$ X $10^{-9} \mathrm{M}$.

\section{DISCUSSION}

To study the $\mathrm{Ca}^{2+}$-dependent/independent properties of binding and activation of target proteins by $\mathrm{CaM}$, numerous studies use a series of $\mathrm{CaM}$ mutants that inhibit $\mathrm{Ca}^{2+}$ binding to the EF hands. These include mutation of Asp to Ala at position 1 of each EF hand in the N-lobe or C-lobe or both lobes. ${ }^{10-13}$ Many studies have expressed $\mathrm{CaM}_{12}, \mathrm{CaM}_{34}$ or $\mathrm{CaM}_{1234}$ in cells to determine if the $\mathrm{Ca}^{2+}$-independent association of $\mathrm{CaM}$ to its target proteins is due to the $\mathrm{Ca}^{2+}$-free $\mathrm{N}$ - or C-lobe of CaM. ${ }^{14-33}$ These point mutations have been reported to result in structural changes in the protein in addition to knocking out its ability to bind $\mathrm{Ca}^{2+}$. Due to the widespread use of these CaM EF mutants, further investigation of their structures in solution was warranted.

The $\mathrm{CaM}_{1234}$ structure was compared to the previously determined solution structure of apoCaM ${ }^{5}$ to determine any structural changes incurred by the Asp to Ala mutations in position 1 of the four EF hands. The biggest structural change observed is in the $\mathrm{Ca}^{2+}$-binding loop of EF hand I. In the apoCaM structure the side chain of Asp20 points into the $\mathrm{Ca}^{2+}$ binding loop and is involved in hydrogen bonds that stabilize the loop. The conversion of Asp to Ala in the $\mathrm{CaM}_{1234}$ structure causes the $\mathrm{Ca}^{2+}$ binding loop to have a less defined structure by eliminating these hydrogen bonds and disrupting the antiparallel $\beta$-sheets connecting EF hands I and II. This also causes the loop and helix B to tilt away from the loop of EF hand II. 
The $\mathrm{Ca}^{2+}$-binding loop of EF hand II also displays structural changes, however these aren't as large as those observed for EF hand I. In the apoCaM structure the side chain of Asp56 is exposed to the solvent, thus doesn't have as large of a role in stabilizing the loop structure and could explain the lower degree of structural change. In the $\mathrm{CaM}_{1234}$ structure the substituted Ala56 side chain points into the loop, disrupting the $\alpha$-helix that Asp56 adopted, unraveling the loop slightly and tilting helix $\mathrm{C}$ towards helix $\mathrm{D}$. The linker region displays similar $\alpha$-helical secondary structure for helices $\mathrm{D}$ and $\mathrm{E}$, with a hinge region at residue 80 for both structures.

As in the case of EF hand I, the side chain of Asp93 of EF hand III points into the loop, however, the mutation to Ala doesn't cause as large of a structure perturbation as Asp20 to Ala. The packing of the Ala side chain into the loop toward the other hydrophobic side chain groups causes the loop to bulge compared to apoCaM. The Asp129 to Ala mutation causes more subtle changes in the $\mathrm{Ca}^{2+}$-binding loop of EF hand IV and helix G. The loop region connecting the two EF hands has a slightly different conformation due to helix $\mathrm{G}$ being tilted inward. Overall the Nlobe mutations cause more overall conformational changes compared to the C-lobe, as evidenced by the higher r.m.s.d. value for the lobe and the aforementioned differences. These structural changes also correlate well with the chemical shift differences observed between the structures, which shows the $\mathrm{N}$-lobe of $\mathrm{CaM}_{1234}$ has larger differences in the $\mathrm{Ca}^{2+}$-binding loops, but fewer differences in the rest of the $\mathrm{N}$-lobe, whereas the C-lobe shows lower chemical shift difference values in the $\mathrm{Ca}^{2+}$-binding loop but a larger amount of subtle differences throughout the whole lobe.

These structural changes also cause electrostatic changes on the surface of CaM, which may affect how $\mathrm{CaM}_{1234}$ interacts with CaM's target enzymes outside of their CaM binding domains. It has previously been shown that CaM lobe surface interactions with regions of its target 
enzymes outside of their CaM binding domains are integral for full enzyme activity. ${ }^{67-71}$ Even though $\mathrm{CaM}_{1234}$ mimics the $\mathrm{Ca}^{2+}$ free nature of apoCaM, the changes in electrostatic surface potential may not allow for full native-like apoCaM interactions with CaM's target proteins.

The solution structure of $\mathrm{CaM}_{34}$ bound to iNOS was determined to investigate if these CaM mutants affected the interaction of CaM with target proteins known to interact with apoCaM. The complex of $\mathrm{CaM}_{34}$ with iNOS was chosen for several reasons. First, binding of CaM to iNOS is $\mathrm{Ca}^{2+}$-independent, so a complex will be formed even with the $\mathrm{Ca}^{2+}$-deplete $\mathrm{C}$-lobe. Second, it would allow us to determine if the EF hand III and IV mutations cause structural changes in the $\mathrm{N}$-lobe as observed from the chemical shift differences between holoCaM and $\mathrm{Ca}^{2+}-\mathrm{CaM}_{34}$ in Fig. 1E. Finally, because in previous iNOS activation studies with the mutant CaMs, $\mathrm{CaM}_{34}$ was the only one to have differences in activation of iNOS in the presence and absence of $\mathrm{Ca}^{2+} \cdot{ }^{24}$

The $\mathrm{CaM}_{34}$-iNOS structure was compared to the previously determined solution structures of holoCaM-iNOS apoCaM. The N-lobes of $\mathrm{CaM}_{34}$ and the iNOS peptides are quite similar to the holoCaM-iNOS structure, whereas the $\mathrm{Ca}^{2+}$ binding loops of EF hands III and IV display differences between the structures. The mutation of Asp to Ala removes the oxygen ligand necessary to coordinate a $\mathrm{Ca}^{2+}$ ion and causes the $\mathrm{Ca}^{2+}$ binding loops of EF hands III and IV to adopt a less compact conformation in the $\mathrm{CaM}_{34}$-iNOS structure. This causes local structural changes, such as the loop region connecting EF hands III and IV to move closer to the iNOS peptide, and long range structural conformation changes, observed in the loop region connecting EF hands I and II and helix B. The loop regions connecting EF hands I and II and connecting EF hands III and IV contain multiple hydrophobic residues that pack close together and interact with the hydrophobic residues of the iNOS peptide. This may account for the amide chemical shift 
changes in the $\mathrm{N}$-domain of $\mathrm{Ca}^{2+}$-saturated $\mathrm{CaM}_{34}$ that were previously observed. ${ }^{13}$ The $\mathrm{EF}$ hands of the $\mathrm{C}$-lobe of $\mathrm{CaM}_{34}$ have a $\mathrm{Ca}^{2+}$-deplete conformation for the $\mathrm{Ca}^{2+}$-binding loop similar to apoCaM; however the interaction with the highly hydrophobic iNOS peptide causes the overall conformation of the helix-loop-helix motifs to be similar to the "open" conformation observed in the $\mathrm{Ca}^{2+}$-replete form. The mutations also cause a decrease in the electronegative surface potential of CaM's C-lobe, which may cause nonnative-like apoCaM interactions with other regions of the iNOS enzyme. These structures can be used to explain previous iNOS activity studies using $\mathrm{CaM}$ and the $\mathrm{Ca}^{2+}$ deficient $\mathrm{CaM}$ mutants.

One of these studies found that iNOS was active for both $\mathrm{CaM}_{34}$ and $\mathrm{CaM}_{12}$, with $\mathrm{CaM}_{34}$ rates similar to holoCaM and $\mathrm{CaM}_{12}$ rates similar to apoCaM, in the presence of $\mathrm{Ca}^{2+}$, whereas $\mathrm{CaM}_{1234}$ produced significantly reduced rates. In the presence of EDTA a substantial decrease in iNOS activity was found for wild type $\mathrm{CaM}$ and $\mathrm{CaM}_{34}$, whereas no substantial decrease in iNOS activity was found for $\mathrm{CaM}_{12}$ or $\mathrm{CaM}_{1234}{ }^{24}$ For full activation of iNOS by $\mathrm{CaM}$ it has been shown that not only is binding of CaM to iNOS' CaM binding domain required, but interaction of CaM with both the oxygenase and reductase domains of iNOS is also required to stabilize the iNOS output state ${ }^{69,70,62}$ The interaction of CaM with iNOS is largely electrostatic; with the positive residues at the heme and FMN domain interfaces interacting with the negative residues of CaM's N- and C-lobes. ${ }^{68,72,73}$ Molecular dynamics, X-ray crystallography and electron cryomicroscopy studies have been used to determine key interactions between $\mathrm{CaM}$ residues and residues of the FMN and both heme domains of the homodimer in the input and output states (supplemental Table S1). ${ }^{68,71-73}$ Some potential important connections required for full activity of iNOS are: Glu47 of CaM with Arg536 of the FMN domain; Asp122 of CaM with Arg83 and Arg86 of the inter monomer heme domain; and Arg106 of CaM with Glu285 of the intra 
monomer heme domain. These studies also showed that CaM undergoes conformational changes, along with the FMN and heme domains, from the input to the output state. During the movement of the FMN domain to the output state the EF hand loops III and IV move by about 2 $\AA$ and $5 \AA$, respectively, due to the shifting of the CaM binding domain, while the N-lobe has a much larger conformational change, due to its interaction with the FMN domain. ${ }^{73}$ All of these interactions, in addition to others observed (supplemental Table S1), are kept fully intact in the $\mathrm{CaM}_{34}$-iNOS structure. The $\mathrm{CaM}_{34}$ mutation causes the conformation of the $\mathrm{C}$-lobe of CaM to resemble that of CaM interacting with the heme domain in the output state, specifically $\operatorname{Arg} 106$ of EF hand III moves about $3 \AA$ and residues Glu122 and Glu127 of EF hand IV move about $6 \AA$ and $5 \AA$, respectively (Fig. 8). Meanwhile, helix $\mathrm{E}$ of the $\mathrm{C}$-lobe of $\mathrm{CaM}_{34}$, which is found to interact with the FMN domain, does not move relative to holoCaM. The $\mathrm{CaM}_{34}$ mutation may cause the C-lobe of CaM to be in a conformation that has interactions which stabilizes the output state conformation of the heme domains, while still allowing the unaffected N-lobe of CaM to have the conformational movement with the FMN domain that is necessary to facilitate the inter domain electron transfer. The N-lobe of the $\mathrm{CaM}_{34}$-iNOS structure is bound to iNOS in the same conformation as holoCaM (Figs. 6 and 8), which explains the full activity of iNOS in the presence of $\mathrm{Ca}^{2+}$. Also the $\mathrm{N}$-lobe of $\mathrm{CaM}$ alone has previously been shown to activate the iNOS enzyme in the presence of $\mathrm{Ca}^{2+}$, thus its tight association with iNOS is enough to fully activate iNOS. ${ }^{68,74,75}$

The reduced iNOS activity observed for $\mathrm{CaM}_{34}$ in the presence of EDTA could be caused by the rearrangement of EF hands I and II due to the removal of $\mathrm{Ca}^{2+}$ from the N-lobe, which would affect the residues of helix $\mathrm{C}$ (Fig. 8) that interact with the FMN domain. This conformational change, coupled with the affected conformation of the loop region between EF hands I and II due 
to the $\mathrm{CaM}_{34}$ mutation, may not allow for the necessary interactions of the N-lobe of CaM to the FMN domain of iNOS required for efficient electron transfer, although CaM is still bound to the $\mathrm{CaM}$ binding domain of the enzyme due to strong hydrophobic interactions. This may prevent the FMN conformational change required for efficient electron transfer to the heme domain or prevent CaM from stabilizing the FMN to heme electron transfer in the "output" state. .1,71,72,76 $^{\text {(1) }}$

The structural rationale for the lower activity observed for $\mathrm{CaM}_{1234}$ with iNOS can be explained by comparing the structure of apoCaM to $\mathrm{CaM}_{1234}$. Although $\mathrm{CaM}_{1234}$ is still able to bind to the highly hydrophobic CaM-binding domain of iNOS, the structural perturbations and electrostatic surface potential changes induced by the EF hand mutations may affect how $\mathrm{CaM}_{1234}$ interacts with the rest of iNOS, specifically CaM's N-lobe interaction with the FMN domain. The less hydrophilic and less negative electrostatic surface of $\mathrm{CaM}_{1234}$ would affect its interaction with the positive surface residues of iNOS at the CaM-FMN interface, which have previously been shown to be necessary for full activation of iNOS. ${ }^{69,72,73}$ This would prevent CaM's stabilizing interaction with the FMN and heme domains in the output state of holoCaM with iNOS. The lower activity of iNOS with $\mathrm{CaM}_{12}$ in the presence and absence of $\mathrm{Ca}^{2+}$ may also be due to the structural and electrostatic changes in the CaM N-lobe as discussed above.

The $\mathrm{K}_{\mathrm{D}}$ of CaM binding to the iNOS peptide is in good agreement with previously reported values that range from $<0.1-3.3 \times 10^{-9} \mathrm{M}^{61-65}$ Previous NMR studies have suggested that at the $17 \mathrm{nM}$ free $\mathrm{Ca}^{2+}$ concentration iNOS increases CaM's affinity for $\mathrm{Ca}^{2+}$ and has a $\mathrm{Ca}^{2+}$-replete $\mathrm{CaM}$ structure. ${ }^{66}$ The binding kinetics at $17 \mathrm{nM}$ free $\mathrm{Ca}^{2+}$ concentration are slower than at saturating $\mathrm{Ca}^{2+}$ concentrations due to $\mathrm{CaM}$ having to bind to $\mathrm{Ca}^{2+}$ and the iNOS peptide, whereas at the saturating $\mathrm{Ca}^{2+}$ concentration $\mathrm{CaM}$ is already $\mathrm{Ca}^{2+}$-replete and in the correct conformation for binding to iNOS. The slower on and off rates observed for $\mathrm{CaM}_{1234}$ binding to iNOS compared to $\mathrm{CaM}$ at both $17 \mathrm{nM}$ free $\mathrm{Ca}^{2+}$ and saturated $\mathrm{Ca}^{2+}$ 
concentration could be explained by the structural perturbations introduced in the N-lobe EF Hands that prevent $\mathrm{CaM}$ from adopting the correct $\mathrm{Ca}^{2+}$-replete conformation necessary for optimum binding to iNOS. The fully intact N-lobe of $\mathrm{CaM}_{34}$ would explain why it has a higher on rate when binding to the iNOS peptide. This is consistent with previous work that has shown only the N-lobe of CaM is necessary for its tight association with iNOS. ${ }^{68,74,75}$

In summary, mutations in the $\mathrm{EF}$ hands of $\mathrm{CaM}$ to disable $\mathrm{Ca}^{2+}$-binding also cause slight structural perturbations, shown in this study by the use of NMR spectroscopy. The structure determination of $\mathrm{CaM}_{1234}$ revealed that the mutation of Asp to Ala causes the EF hand loops to adopt perturbed conformations when compared to apoCaM, with the greatest effect seen in EF Hand I. The structure also displayed a less stable C-lobe compared to N-lobe as previously observed for apoCaM. To investigate if these mutations also perturb the structure of CaM bound to a target peptide the structure of $\mathrm{CaM}_{34}$ bound to the iNOS peptide was determined. The mutation of Asp to Ala causes the $\mathrm{Ca}^{2+}$ binding loops in the $\mathrm{C}$-lobe $\mathrm{EF}$ hands to adopt a conformation resembling apoCaM, which causes local structural changes, as shown in the loop region connecting EF hands III and IV, and long range structural conformation changes, as shown in the loop region connecting EF hands I and II and helix B. These changes may cause $\mathrm{CaM}$ to adopt conformations not truly representative of apoCaM. This study provides structural evidence of changes that are present in CaM mutants with mutations at Asp in position 1 of the EF hand. These mutations also increase the hydrophobic exposed surface and decrease the electronegative surface potential throughout each lobe of CaM. To investigate whether the small structural differences between apoCaM and $\mathrm{CaM}_{1234}$ result in appreciable changes in biding kinetics with the iNOS peptide we performed SPR experiments on the different CaM proteins. Both the on and off rates for $\mathrm{CaM}_{1234}$ binding to the iNOS peptide were significantly slower than to CaM at both $17 \mathrm{nM}$ free 
$\mathrm{Ca}^{2+}$ and saturated $\mathrm{Ca}^{2+}$ concentration. The differences in binding kinetics with $\mathrm{CaM}$ at basal $\mathrm{Ca}^{2+}$ levels are significant as they provide further reason to carefully scrutinize experiments that use $\mathrm{CaM}_{1234}$ to represent the $\mathrm{Ca}^{2+}$-free form of the protein. These $\mathrm{Ca}^{2+}$ deficient $\mathrm{CaM}$ mutants may not be a true representation of apoCaM and may not allow for native-like interactions of apoCaM with its target proteins.

\section{ACKNOWLEDGMENTS}

The authors would like to thank John Dick from Nicoya Lifesciences for providing the streptavidin sensor chips for the SPR experiments. Molecular graphics images were produced using the UCSF Chimera package from the Resource for Biocomputing, Visualization, and Informatics at the University of California, San Francisco. Plasmids coding for $\mathrm{CaM}_{12}, \mathrm{CaM}_{34}$ and $\mathrm{CaM}_{1234}$ were a generous gift from Dr. John Adelman (Oregon Health \& Sciences University, Portland, OR, USA).

\section{SUPPORTING INFORMATION}

Superposition of ${ }^{1} \mathrm{H}_{-}{ }^{15} \mathrm{~N}$ HSQC spectra of apo and $\mathrm{Ca}^{2+}$-saturated wild type $\mathrm{CaM}, \mathrm{CaM}_{12}$ and $\mathrm{CaM}_{34}$, superposition of ${ }^{1} \mathrm{H}-{ }^{15} \mathrm{~N}$ HSQC spectra of $\mathrm{CaM}_{1234}$ and apoCaM, superposition of ${ }^{1} \mathrm{H}-{ }^{15} \mathrm{~N}$ HSQC spectra of $\mathrm{CaM}_{34}$-iNOS and holoCaM-iNOS, electrostatic surface representations of CaM-iNOS and $\mathrm{CaM}_{34}$-iNOS, SPR sensorgrams of the binding of $\mathrm{CaM}, \mathrm{CaM}_{1234} \mathrm{CaM}_{34}$ onto immobilized iNOS peptide, residue-residue interaction of CaM with the iNOS heme and FMN domains. 


\section{REFERENCES}

(1) Ikura, M., and Ames, J. B. (2006) Genetic polymorphism and protein conformational plasticity in the calmodulin superfamily: two ways to promote multifunctionality. Proc. Natl. Acad. Sci. U. S. A. 103, 1159-1164.

(2) Persechini, A., and Kretsinger, R. H. (1988) The central helix of calmodulin functions as a flexible tether. J. Biol. Chem. 263, 12175-12178.

(3) Strynadka, N. C. J., and James, M. N. G. (1989) Crystal structures of the helix-loop-helix calcium-binding proteins. Annu. Rev. Biochem. 58, 951-998.

(4) Zhang, M., Tanaka, T., and Ikura, M. (1995) Calcium-induced conformational transition revealed by the solution structure of apo calmodulin. Nat. Struct. Biol. 2, 758-767.

(5) Kuboniwa, H., Tjandra, N., Grzesiek, S., Ren, H., Klee, C. B., and Bax, A. (1995) Solution structure of calcium-free calmodulin. Nat. Struct. Biol. 2, 768-776.

(6) Babu, Y. S., Bugg, C. E., and Cook, W. J. (1988) Structure of calmodulin refined at $2.2 \AA$ resolution. J. Mol. Biol. 204, 191-204.

(7) Jurado, L. a, Chockalingam, P. S., and Jarrett, H. W. (1999) Apocalmodulin. Physiol. Rev. $79,661-682$.

(8) Tidow, H., and Nissen, P. (2013) Structural diversity of calmodulin binding to its target sites. FEBS J. 280, 5551-5565.

(9) Mruk, K., Farley, B. M., Ritacco, A. W., and Kobertz, W. R. (2014) Calmodulation metaanalysis: Predicting calmodulin binding via canonical motif clustering. J. Gen. Physiol. 144, $105-114$.

(10) Putkey, J. a, Sweeney, H. L., and Campbell, S. T. (1989) Site-directed mutation of the trigger calcium-binding sites in cardiac troponin C. J. Biol. Chem. 264, 12370-12378.

(11) Geiser, J. R., van Tuinen, D., Brockerhoff, S. E., Neff, M. M., and Davis, T. N. (1991) Can calmodulin function without binding calcium? Cell 65, 949-959.

(12) Xia, X. M., Fakler, B., Rivard, A., Wayman, G., Johnson-Pais, T., Keen, J. E., Ishii, T., Hirschberg, B., Bond, C. T., Lutsenko, S., Maylie, J., and Adelman, J. P. (1998) Mechanism of calcium gating in small-conductance calcium-activated potassium channels. Nature 395, 503507.

(13) Xiong, L.-W., Kleerekoper, Q. K., Wang, X., and Putkey, J. a. (2010) Intra- and interdomain effects due to mutation of calcium-binding sites in calmodulin. J. Biol. Chem. 285, 8094-8103.

(14) Sachyani, D., Dvir, M., Strulovich, R., Tria, G., Pongs, O., Svergun, D., Attali, B., and Hirsch, J. a. (2014) Structural basis of a Kv7.1 potassium channel gating module: studies of the intracellular C-terminal domain in complex with calmodulin. Structure 22, 1582-1594.

(15) Yang, T., He, L.-L., Chen, M., Fang, K., and Colecraft, H. M. (2013) Bio-inspired voltagedependent calcium channel blockers. Nat. Commun. 4, 1-10. 
(16) Adams, P. J., Ben-Johny, M., Dick, I. E., Inoue, T., and Yue, D. T. (2014) Apocalmodulin itself promotes ion channel opening and $\mathrm{Ca}^{2+}$ regulation. Cell 159, 608-622.

(17) Ben-Johny, M., Yang, P. S., Niu, J., Yang, W., Joshi-Mukherjee, R., and Yue, D. T. (2014) Conservation of $\mathrm{Ca}^{2+}$ /calmodulin regulation across $\mathrm{Na}$ and $\mathrm{Ca}^{2+}$ channels. Cell 157, 1657-1670.

(18) DeMaria, C. D., Soong, T. W., Alseikhan, B. a, Alvania, R. S., and Yue, D. T. (2001) Calmodulin bifurcates the local $\mathrm{Ca}^{2+}$ signal that modulates P/Q-type $\mathrm{Ca}^{2+}$ channels. Nature 411, 484-489.

(19) Crump, S. M., Andres, D. A., Sievert, G., and Satin, J. (2013) The cardiac L-type calcium channel distal carboxy terminus autoinhibition is regulated by calcium. Am J Physiol Hear. Circ Physiol 304, H455-H464.

(20) Dick, I. E., Tadross, M. R., Liang, H., Tay, L. H., Yang, W., and Yue, D. T. (2008) A modular switch for spatial $\mathrm{Ca}^{2+}$ selectivity in the calmodulin regulation of $\mathrm{CaV}$ channels. Nature $451,830-834$.

(21) Deschenes, I., Neyroud, N., DiSilvestre, D., Eduardo, M., Yue, D. T., and Tomaselli, G. F. (2002) Isoform-specific modulation of voltage-gated $\mathrm{Na}^{(+)}$channels by calmodulin. Circ. Res. 90, E49-E57.

(22) Kasri, N. N., Sienaert, I., Parys, J. B., Callewaert, G., Missiaen, L., Jeromin, A., and De Smedt, H. (2003) A novel $\mathrm{Ca}^{2+}$-induced $\mathrm{Ca}^{2+}$ release mechanism in A7r5 cells regulated by calmodulin-like proteins. J. Biol. Chem. 278, 27548-27555.

(23) Kasri, N. N., Bultynck, G., Smyth, J., Szlufcik, K., Parys, J. B., Callewaert, G., Missiaen, L., Fissore, R. a, Mikoshiba, K., and de Smedt, H. (2004) The N-terminal Ca ${ }^{2+}$-independent calmodulin-binding site on the inositol 1,4,5-trisphosphate receptor is responsible for calmodulin inhibition, even though this inhibition requires $\mathrm{Ca}^{2+}$. Mol. Pharmacol. 66, 276-284.

(24) Spratt, D. E., Taiakina, V., and Guillemette, J. G. (2007) Calcium-deficient calmodulin binding and activation of neuronal and inducible nitric oxide synthases. Biochim. Biophys. Acta $1774,1351-1358$.

(25) Thorogate, R., and Török, K. (2007) Role of $\mathrm{Ca}^{2+}$ activation and bilobal structure of calmodulin in nuclear and nucleolar localization. Biochem. J. 402, 71-80.

(26) Tien, J., Peters, C. J., Wong, X. M., Cheng, T., Jan, Y. N., and Jan, L. Y. (2014) A comprehensive search for calcium binding sites critical for TMEM16A calcium- activated chloride channel activity. Elife 3, e02772.

(27) Strotmann, R., Semtner, M., Kepura, F., Plant, T. D., and Schöneberg, T. (2010) Interdomain interactions control $\mathrm{Ca}^{2+}$-dependent potentiation in the cation channel TRPV4. PLoS One 5, 1-10.

(28) Ravindran, A., Kobrinsky, E., Lao, Q. Z., and Soldatov, N. M. (2009) Functional properties of the $\mathrm{Ca}_{\mathrm{V}} 1.2$ calcium channel activated by calmodulin in the absence of alpha2delta subunits. Channels (Austin). 3, 25-31.

(29) Chou, A. C., Ju, Y. Ten, Pan, C. Y., and Obukhov, A. G. (2015) Calmodulin interacts with the sodium/calcium exchanger NCX1 to regulate activity. PLoS One 10, e0138856. 
(30) Yang, P. S., Johny, M. B., and Yue, D. T. (2014) Allostery in $\mathrm{Ca}^{2+}$ channel modulation by calcium-binding proteins. Nat Chem Biol 10, 231-238.

(31) Singh, A., Hamedinger, D., Hoda, J.-C., Gebhart, M., Koschak, A., Romanin, C., and Striessnig, J. (2006) C-terminal modulator controls $\mathrm{Ca}^{2+}$-dependent gating of $\mathrm{Ca}_{\mathrm{v}} 1.4 \mathrm{~L}$-type $\mathrm{Ca}^{2+}$ channels. Nat. Neurosci. 9, 1108-1116.

(32) Dick, I. E., Joshi-Mukherjee, R., Yang, W., and Yue, D. T. (2016) Arrhythmogenesis in Timothy Syndrome is associated with defects in $\mathrm{Ca}^{2+}$-dependent inactivation. Nat. Commun. 7 , 10370.

(33) Lee, A., Zhou, H., Scheuer, T., and Catterall, W. a. (2003) Molecular determinants of $\mathrm{Ca}^{2+} /$ calmodulin-dependent regulation of $\mathrm{Ca}_{\mathrm{v}} 2.1$ channels. Proc. Natl. Acad. Sci. U. S. A. 100, 16059-16064.

(34) Lee, W.-S., Ngo-Anh, T. J., Bruening-Wright, A., Maylie, J., and Adelman, J. P. (2003) Small conductance $\mathrm{Ca}^{2+}$-activated $\mathrm{K}+$ channels and calmodulin: cell surface expression and gating. J. Biol. Chem. 278, 25940-25946.

(35) Cho, H. J., Xie, Q. W., Calaycay, J., Mumford, R. a, Swiderek, K. M., Lee, T. D., and Nathan, C. (1992) Calmodulin is a subunit of nitric oxide synthase from macrophages. J. Exp. Med. 176, 599-604.

(36) Xie, Q. W., Cho, H. J., Calacay, J., Mumford, R. A., Swiderek, K. M., Lee, T. D., Ding, A., Troso, T., and Nathan, C. (1992) Cloning and characterization of inducible nitric oxide synthase from mouse macrophages. Science (80-. ). 256, 225-228.

(37) Urbauer, J. L., Short, J. H., Dow, L. K., and Wand, A. J. (1995) Structural analysis of a novel interaction by calmodulin: high-affinity binding of a peptide in the absence of calcium. Biochemistry 34, 8099-8109.

(38) Alderton, W. K., Cooper, C. E., and Knowles, R. G. (2001) Nitric oxide synthases: structure, function and inhibition. Biochem. J. 357, 593-615.

(39) Roman, L. J., Martásek, P., and Masters, B. S. S. (2002) Intrinsic and extrinsic modulation of nitric oxide synthase activity. Chem. Rev. 102, 1179-1190.

(40) Volkmann, N., Martasek, P., Roman, L. J., Xu, X. P., Page, C., Swift, M., Hanein, D., and Masters, B. S. (2014) Holoenzyme structures of endothelial nitric oxide synthase - An allosteric role for calmodulin in pivoting the FMN domain for electron transfer. J. Struct. Biol. 188, 46-54.

(41) Sobolewska-Stawiarz, A., Leferink, N. G. H., Fisher, K., Heyes, D. J., Hay, S., Rigby, S. E. J., and Scrutton, N. S. (2014) Energy landscapes and catalysis in nitric-oxide synthase. J. Biol. Chem. 289, 11725-11738.

(42) Ghosh, D. K., and Salerno, J. C. (2003) Nitric Oxide Synthases: Domain structure and alignment in enzyme function and control. Front. Biosci. 8, D193-D209.

(43) Busse, R., and Mulsch, A. (1990) Calcium-dependent nitric oxide synthesis in endothelial cytosol is mediated by calmodulin. FEBS Lett. 265, 133-136.

(44) Balligand, J.-L., Ungureanu-Longrois, D., Simmons, W. W., Pimental, D., Malinski, T. A., Kapturczak, M., Taha, Z., Lowenstein, C. J., Davidoff, A. J., Kelly, R. A., Smith, T. W., and 
Michel, T. (1994) Cytokine-inducible nitric oxide synthase (iNOS) expression in cardiac myocytes. Characterization and regulation of iNOS expression and detection of iNOS activity in single cardiac myocytes in vitro. J Biol Chem 269, 27580-27588.

(45) Keller, R. L. J. (2005) Optimizing the process of nuclear magnetic resonance spectrum analysis and computer aided resonance assignment. Swiss Federal Institue of Technology Zurich.

(46) Piazza, M., Futrega, K., Spratt, D. E., Dieckmann, T., and Guillemette, J. G. (2012) Structure and dynamics of calmodulin $(\mathrm{CaM})$ bound to nitric oxide synthase peptides: Effects of a phosphomimetic caM mutation. Biochemistry 51, 3651-3661.

(47) Grzesiek, S., and Bax, A. (1992) An efficient experiment for sequential backbone assignment of medium-sized isotopically enriched proteins. J. Magn. Reson. 99, 201-207.

(48) Grzesiek, S., and Bax, A. (1992) Correlating backbone amide and side chain resonances in larger proteins by multiple relayed triple resonance NMR. J. Am. Chem. Soc. 114, 6291-6293.

(49) Muhandiram, D. R., and Kay, L. E. (1994) Gradient-enhanced triple-resonance 3dimensional NMR experiments with improved sensitivity. J. Magn. Reson. 103, 203-216.

(50) Ikura, M., Kay, L. E., and Bax, A. (1990) A novel approach for sequential assignment of ${ }^{1} \mathrm{H}$, ${ }^{13} \mathrm{C}$, and ${ }^{15} \mathrm{~N}$ spectra of proteins: heteronuclear triple-resonance three-dimensional NMR spectroscopy. Application to calmodulin. Biochemistry 29, 4659-4567.

(51) Ikura, M., and Bax, A. (1992) Isotope-filtered 2D NMR of a protein-peptide complex study of a skeletal muscle MLCK fragment bound to calmodulin. J. Am. Chem. Soc. 114, 2433-2440.

(52) Clore, G. M., and Gronenborn, A. M. (1991) Applications of three- and four-dimensional heteronuclear NMR spectroscopy to protein structure determination. Prog. Nucl. Magn. Reson. Spectrosc. 23, 43-92.

(53) Fesik, S. W., and Zuiderweg, E. R. P. (1990) Heteronuclear three-dimensional NMR spectroscopy of isotopically labelled biological macromolecules. Quart. Rev. Biophys 23, 97131.

(54) Brunger, A. T., Adams, P. D., Clore, G. M., Delano, W. L., Gros, P., Grosse-kunstleve, R. W., Jiang, J., Kuszewski, J., Nilges, M., Pannu, N. S., Read, R. J., Rice, L. M., Simonson, T., and Gregory, L. (1998) Crystallography \& NMR system : A new software suite for macromolecular structure determination. Acta Cryst. D54, 905-921.

(55) Dolinsky, T. J., Czodrowski, P., Li, H., Nielsen, J. E., Jensen, J. H., Klebe, G., and Baker, N. A. (2007) PDB2PQR: Expanding and upgrading automated preparation of biomolecular structures for molecular simulations. Nucleic Acids Res. 35, W522-W525.

(56) Dolinsky, T. J., Nielsen, J. E., McCammon, J. A., and Baker, N. A. (2004) PDB2PQR: An automated pipeline for the setup of Poisson-Boltzmann electrostatics calculations. Nucleic Acids Res. 32, W665-W667.

(57) Baker, N. A., Sept, D., Joseph, S., Holst, M. J., and McCammon, J. A. (2001) Electrostatics of nanosystems: application to microtubules and the ribosome. Proc. Natl. Acad. Sci. U. S. A. 98, 10037-10041.

(58) Pettersen, E. F., Goddard, T. D., Huang, C. C., Couch, G. S., Greenblatt, D. M., Meng, E. 
C., and Ferrin, T. E. (2004) UCSF Chimera--A Visualization System for Exploratory Research and Analysis. J.Comput. Chem. 25, 1605-1612.

(59) Kyte, J., and Doolittle, R. F. (1982) A simple method for displaying the hydropathic character of a protein. J. Mol. Biol. 157, 105-132.

(60) Chattopadhyaya, R., Meador, W. E., Means, A. R., and Quiocho, F. A. (1992) Calmodulin structure refined at $1.7 \AA$ resolution. J. Mol. Biol. 228, 1177-1192.

(61) Yuan, T., Vogel, H. J., Sutherland, C., and Walsh, M. P. (1998) Characterization of the $\mathrm{Ca}^{2+}$ -dependent and -independent interactions between calmodulin and its binding domain of inducible nitric oxide synthase. FEBS Lett. 431, 210-214.

(62) Venema, R. C., Sayegh, H. S., Kent, J. D., and Harrison, D. G. (1996) Identification, characterization, and comparison of the calmodulin-binding domains of the endothelial and inducible nitric oxide synthases. J. Biol. Chem. 271, 6435-6440.

(63) Matsubara, M., Hayashi, N., Titani, K., and Taniguchi, H. (1997) Circular dichroism and ${ }^{1} \mathrm{H}$ NMR studies on the structures of peptides derived from the calmodulin-binding domains of inducible and endothelial nitric-oxide synthase in solution and in complex with calmodulin. $J$. Biol. Chem. 272, 23050-23056.

(64) Anagli, J., Hofmann, F., Quadroni, M., Vorherr, T., and Carafoli, E. (1995) The calmodulinbinding domain of the inducible (macrophage) nitric oxide synthase. Eur. J. Biochem. 233, 701708.

(65) Zoche, M., Bienert, M., Beyermann, M., and Koch, K. W. (1996) Distinct molecular recognition of calmodulin-binding sites in the neuronal and macrophage nitric oxide synthases: a surface plasmon resonance study. Biochemistry 35, 8742-8747.

(66) Piazza, M., Guillemette, J. G., and Dieckmann, T. (2015) Dynamics of nitric oxide synthase-calmodulin interactions at physiological calcium concentrations. Biochemistry 54, 1989-2000.

(67) Drum, C. L., Yan, S.-Z., Bard, J., Shen, Y.-Q., Lu, D., Soelaiman, S., Grabarek, Z., Bohm, A., and Tang, W.-J. (2002) Structural basis for the activation of anthrax adenylyl cyclase exotoxin by calmodulin. Nature 415, 396-402.

(68) Xia, C., Misra, I., Iyanagi, T., and Kim, J.-J. P. (2009) Regulation of interdomain interactions by calmodulin in inducible nitric-oxide synthase. J. Biol. Chem. 284, 30708-30717.

(69) Lee, S. J., and Stull, J. T. (1998) Calmodulin-dependent regulation of inducible and neuronal nitric-oxide synthase. J. Biol. Chem. 273, 27430-27437.

(70) Ruan, J., Xie, Q. W., Hutchinson, N., Cho, H., Wolfe, G. C., and Nathan, C. (1996) Inducible nitric oxide synthase requires both the canonical calmodulin-binding domain and additional sequences in order to bind calmodulin and produce nitric oxide in the absence of free $\mathrm{Ca}^{2+}$. J. Biol. Chem. 271, 22679-22686.

(71) Hollingsworth, S. A., Holden, J. K., Li, H., and Poulos, T. L. (2016) Elucidating nitric oxide synthase domain interactions by molecular dynamics. Protein Sci. 25, 374-382.

(72) Smith, B. C., Underbakke, E. S., Kulp, D. W., Schief, W. R., and Marletta, M. A. (2013) 
Nitric oxide synthase domain interfaces regulate electron transfer and calmodulin activation. Proc. Natl. Acad. Sci. U. S. A. 110, E3577-E3586.

(73) Sheng, Y., Zhong, L., Guo, D., Lau, G., and Feng, C. (2015) Insight into structural rearrangements and interdomain interactions related to electron transfer between flavin mononucleotide and heme in nitric oxide synthase: A molecular dynamics study. J. Inorg. Biochem. 153, 186-196.

(74) Spratt, D. E., Taiakina, V., Palmer, M., and Guillemette, J. G. (2007) Differential binding of calmodulin domains to constitutive and inducible nitric oxide synthase enzymes. Biochemistry $46,8288-8300$.

(75) Spratt, D. E., Newman, E., Mosher, J., Ghosh, D. K., Salerno, J. C., and Guillemette, J. G. (2006) Binding and activation of nitric oxide synthase isozymes by calmodulin EF hand pairs. FEBS J. 273, 1759-1771.

(76) Leferink, N. G. H., Hay, S., Rigby, S. E. J., and Scrutton, N. S. (2014) Towards the free energy landscape for catalysis in mammalian nitric oxide synthases. FEBS J. 282, 3016-3029. 
Table 1: Statistics for the structural ensemble of $\mathrm{CaM}_{1234}$.

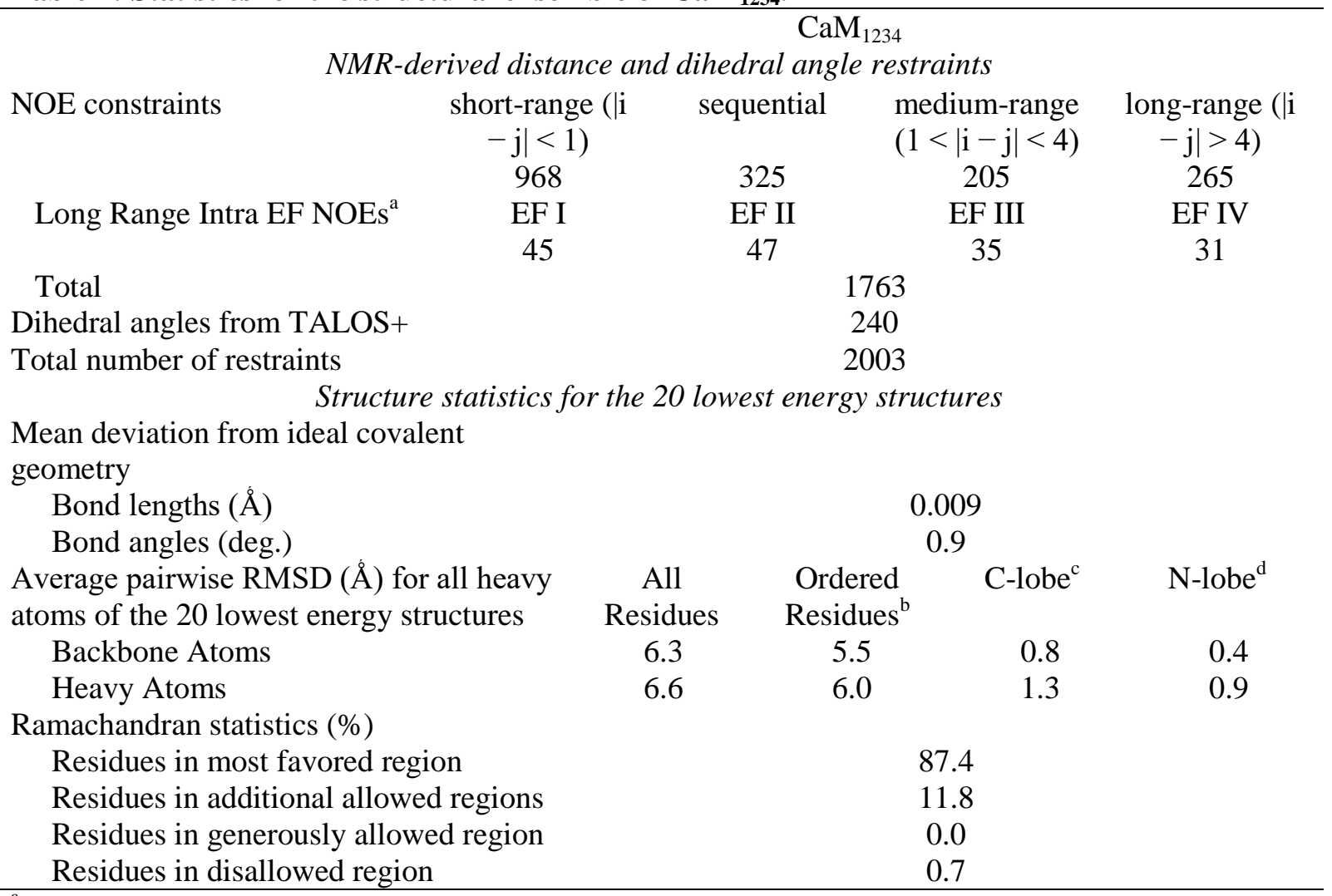

${ }^{a}$ Long range NOEs observed between residues in the same EF Hand

${ }^{\mathrm{b}}$ Ordered residue ranges: 4A-20A,24A-57A,61A-79A,81A-92A,101A-112A,117A-129A, 132A-147A

${ }^{\mathrm{c}} \mathrm{C}$-lobe residues: $81 \mathrm{~A}-148 \mathrm{~A}$

${ }^{\mathrm{d}} \mathrm{N}$-lobe residues: $4 \mathrm{~A}-74 \mathrm{~A}$ 
Table 2: Statistics for the structural ensemble of the $\mathrm{CaM}_{34}$-iNOS peptide complex.

\begin{tabular}{|c|c|c|c|c|c|}
\hline \multicolumn{6}{|c|}{$\begin{array}{r}\mathrm{CaM}_{34}-\mathrm{iNOS} \text { Complex } \\
\text { NMR-derived distance and dihedral angle restraints }\end{array}$} \\
\hline & \multicolumn{2}{|c|}{$\begin{array}{l}\text { distance and dih } \\
\mathrm{CaM}_{34}\end{array}$} & NOS peptide & \multicolumn{2}{|c|}{$\mathrm{CaM}_{34}$-iNOS complex } \\
\hline \multicolumn{6}{|l|}{ NOE constraints } \\
\hline short-range $(|i-j|<1)$ & \multicolumn{2}{|c|}{821} & 125 & \multicolumn{2}{|r|}{ N/A } \\
\hline sequential & \multicolumn{2}{|c|}{497} & 52 & \multicolumn{2}{|r|}{ N/A } \\
\hline medium-range $(1<|i-j|<4)$ & \multicolumn{2}{|c|}{240} & 33 & \multicolumn{2}{|r|}{ N/A } \\
\hline long-range $(|i-j|>4)$ & \multicolumn{2}{|c|}{160} & 4 & \multicolumn{2}{|r|}{82} \\
\hline Total & \multicolumn{2}{|c|}{1718} & 214 & \multicolumn{2}{|r|}{82} \\
\hline Dihedral angles from TALOS+ & \multicolumn{2}{|c|}{262} & N/A & \multicolumn{2}{|r|}{ N/A } \\
\hline Total number of restraints & & & 2276 & & \\
\hline \multicolumn{6}{|c|}{ Structure statistics for the 20 lowest energy structures } \\
\hline \multicolumn{6}{|c|}{$\begin{array}{l}\text { Mean deviation from ideal covalent } \\
\text { geometry }\end{array}$} \\
\hline Bond lengths $(\AA ̊)$ & \multicolumn{5}{|c|}{0.010} \\
\hline Bond angles (deg.) & \multicolumn{5}{|c|}{1.2} \\
\hline \multicolumn{2}{|c|}{$\begin{array}{l}\text { Average pairwise RMSD }(\AA) \text { for all heavy } \\
\text { atoms of the } 20 \text { lowest energy structures }\end{array}$} & $\begin{array}{c}\text { All } \\
\text { Residues }\end{array}$ & $\begin{array}{l}\text { Ordered } \\
\text { Residues }^{\mathrm{a}}\end{array}$ & C-lobe ${ }^{b}$ & N-lobe ${ }^{c}$ \\
\hline Backbone Atoms & & 1.3 & 1.0 & 1.0 & 0.7 \\
\hline Heavy Atoms & & 1.7 & 1.4 & 1.6 & 1.2 \\
\hline \multicolumn{6}{|l|}{ Ramachandran statistics $(\%)$} \\
\hline Residues in most favored reg & & & & & \\
\hline Residues in additional allowe & ons & & & & \\
\hline Residues in generously allow & & & & & \\
\hline Residues in disallowed regior & & & & & \\
\hline
\end{tabular}

\footnotetext{
${ }^{a}$ Ordered residue ranges: 5A-42A, 44A-92A, 100A-147A, 517B-528B

${ }^{\mathrm{b}} \mathrm{C}$-lobe residues: 81A-148A

${ }^{\mathrm{c}} \mathrm{N}$-lobe residues: $4 \mathrm{~A}-74 \mathrm{~A}$
} 
Table 3. $k_{\text {on }}$ and $k_{\text {off }}$ rate constants of iNOS target peptide to CaM in the presence of $17 \mathrm{nM}$ free $\mathrm{Ca}^{2+}$ and saturating $(1 \mathrm{mM}) \mathrm{Ca}^{2+}$.

\begin{tabular}{llll}
\hline Saturating $\mathbf{C a}^{2+}$ & $\mathbf{k}_{\text {on }}\left(\mathbf{1 0}^{\mathbf{4}} \mathbf{M}^{-1} \mathbf{s}^{-1}\right)^{\mathbf{a}}$ & $\mathbf{k}_{\text {off }}\left(\mathbf{1 0}^{-4} \mathbf{s}^{-1}\right)^{\mathbf{a}}$ & $\mathbf{K}_{\mathbf{D}}\left(\mathbf{1 0}^{-\mathbf{9}} \mathbf{M}\right)^{\mathbf{a}}$ \\
\hline CaM-iNOS & $27.5 \pm 0.01$ & $3.9 \pm 0.02$ & $1.4 \pm 0.01$ \\
$\mathrm{CaM}_{1234}$-iNOS & $6.4 \pm 0.1$ & $1.9 \pm 0.03$ & $2.9 \pm 0.1$ \\
$\mathrm{CaM}_{34}$-iNOS & $44.2 \pm 0.01$ & $8.5 \pm 0.04$ & $1.9 \pm 0.01$ \\
\hline $\mathbf{1 7} \mathbf{~ n M ~ f r e e ~} \mathbf{C a}^{2+}$ & $\mathbf{k}_{\text {on }}\left(\mathbf{1 0}^{4} \mathbf{M}^{-1} \mathbf{s}^{-1}\right)^{\mathbf{a}}$ & $\mathbf{k}_{\text {off }}\left(\mathbf{1 0}^{-4} \mathbf{s}^{-1}\right)^{\mathbf{a}}$ & $\mathbf{K}_{\mathbf{D}}\left(\mathbf{1 0} \mathbf{M}^{-\mathbf{a}}\right.$ \\
\hline CaM-iNOS & $20.5 \pm 0.04$ & $14.5 \pm 0.2$ & $7.1 \pm 1.0$
\end{tabular}

${ }^{a}$ Data was fit in TraceDrawer using a 1:1 binding interaction model $(\mathrm{A}+\mathrm{B} \leftrightarrow \mathrm{AB})$ with errors from TraceDrawer. 


\section{FIGURE CAPTIONS}

FIGURE 1. Chemical shift differences for the amide chemical shifts between (A) $\mathrm{CaM}_{1234}$ and $\operatorname{apoCaM}(\mathrm{B})$ apoCaM and $\operatorname{apoCaM}_{12},(\mathrm{C})$ apoCaM and $\operatorname{apoCaM}_{34},(\mathrm{D})$ holoCaM and $\mathrm{Ca}^{2+}-$ $\mathrm{CaM}_{12}$, and (E) holoCaM and $\mathrm{Ca}^{2+}-\mathrm{CaM}_{34}$ are shown. The insets in $\mathrm{D}$ and $\mathrm{E}$ show the chemical shift differences of the C-lobe for holoCaM and $\mathrm{Ca}^{2+}-\mathrm{CaM}_{12}$ and N-lobe for holoCaM and $\mathrm{Ca}^{2+}$ $\mathrm{CaM}_{34}$, respectively. The greatest differences are localized to $\mathrm{Ca}^{2+}$ binding loops where each mutation is present. In the presence of $\mathrm{Ca}^{2+}$ some chemical shift differences occur for the lobe opposite the mutation sites. The contribution of ${ }^{1} \mathrm{HN}$ and ${ }^{15} \mathrm{~N}$ chemical shift changes for each residue was calculated as $\Delta \delta=\sqrt{ }\left[\left(\Delta \delta^{1} \mathrm{HN}\right)^{2}+\left(\Delta \delta^{15} \mathrm{~N} / 5\right)^{2}\right]$, where $\Delta \delta^{1} \mathrm{HN}$ and $\Delta \delta^{15} \mathrm{~N}$ are the differences in ${ }^{1} \mathrm{HN}$ and ${ }^{15} \mathrm{~N}$ chemical shifts between the indicated protein.

FIGURE 2. Solution structure of $\mathrm{CaM}_{1234}$. The superposition of the ensemble of the 20 lowestenergy calculated solution structures of $\mathrm{CaM}_{1234}$.(A) The $\mathrm{N}$-terminal domain is superimposed against the energy-minimized average structure. (B) The C-terminal domain is superimposed against the energy-minimized average structure. (C) Cartoon ribbon view of the energyminimized average solution structure of the $\mathrm{CaM}_{1234}$. Residues $1-40$ of $\mathrm{CaM}$ (EF hand I) are colored red, residues 41-79 (EF hand II) purple, residues 80-114 (EF hand III) green, and residues 115-148 (EF hand IV) blue.

FIGURE 3. Comparison of the solution structure of the $\mathrm{CaM}_{1234}$ with the solution structure of apoCaM. The solution structures of $\mathrm{CaM}_{1234}$ (dark colors) and apoCaM (light colors, Structure from PDB 1CFD (5)) are overlaid. For clarity only the N-lobes of $\mathrm{CaM}_{1234}$ and apoCaM were superimposed in A and B and the C-lobes superimposed in C and D. The side chains of Asp in apoCaM and Ala in $\mathrm{CaM}_{1234}$ are shown and labeled as D20A, D56A, D93A and D129A. The 
superimposed structures are viewed from EF Hand I to IV in panels A to D. The color scheme is the same as Fig. 2.

FIGURE 4. Electrostatic and hydrophobicity surface representations of apoCaM and $\mathrm{CaM}_{1234}$. The APBS-calculated electrostatic potential maps projected on the surface of (A, B) apoCaM (Solution structure from PDB $1 \mathrm{CFD}(5))$ and (D, E) the $\mathrm{CaM}_{1234}$ solution structure. The hydrophobicity surface calculated in chimera, using the Kyte-Doolittle scale, projected onto (C) apoCaM and $(\mathrm{F})$ the $\mathrm{CaM}_{1234}$ solution structures. The electrostatic potential maps are colored with a chimera color key ranging from red (acidic, -10) to blue (basic, 10). The hydrophobicity surface is colored from blue (4.5) for the most hydrophilic, to white, to orange red (-4.5) for the most hydrophobic. The mutation sites D20A, D56A, D93A and D129A are labeled and indicated by $*$.

FIGURE 5. Solution structure of the $\mathrm{CaM}_{34}$-iNOS complex. (A) Superposition of the ensemble of the 20 lowest-energy calculated NMR solution structures of $\mathrm{CaM}_{34}$ bound to the iNOS peptide. Backbone atom traces of $\mathrm{CaM}$ are colored dark blue, and the iNOS peptide colored light blue. (B) Cartoon ribbon view of the average solution structure of the $\mathrm{CaM}_{34}$-iNOS complex. CaM has the same color scheme as Fig. 2. The peptide is colored lighter blue.

FIGURE 6. (A-D) Comparison of the solution structures of the $\mathrm{CaM}_{34}$-iNOS peptide complex and the holoCaM-iNOS peptide complex. The solution structures of the $\mathrm{CaM}_{34}$-iNOS peptide (dark colors) and holoCaM-iNOS (light colors) are aligned by superimposition of the backbone atoms of the N-lobes of $\mathrm{CaM}$ and the iNOS peptides viewed along the bound peptide from its $\mathrm{C}$ terminus $\left(\mathrm{C}^{\prime}\right)$ to its $\mathrm{N}$-terminus $\left(\mathrm{N}^{\prime}\right)$ in $\mathrm{A}$ and subsequently rotated $90^{\circ}$ around the vertical axis in B. The superposition is viewed along the bound peptide from its $\mathrm{N}$-terminus $\left(\mathrm{N}^{\prime}\right)$ to its $\mathrm{C}$ terminus $\left(\mathrm{C}^{\prime}\right)$ in $\mathrm{C}$ and subsequently rotated $90^{\circ}$ around the vertical axis in D. Calcium ions were 
omitted for clarity. (E, F) Comparison of the C-terminal residues of the solution structures of the $\mathrm{CaM}_{34}$-iNOS peptide complex and apoCaM. The solution structures of the $\mathrm{CaM}_{34}$-iNOS peptide (dark colors) and apoCaM (light colors) are aligned by superimposition of the backbone atoms of the C-lobes of CaM. The superimposed structures are viewed along the EF hand III and IV interface in $\mathrm{E}$ and viewed along the side of EF Hand IV in F. The N-lobes and the iNOS peptide have been removed for clarity. The color scheme is the same as Fig. 2.

FIGURE 7. Electrostatic and hydrophobicity surface representations of CaM-iNOS and $\mathrm{CaM}_{34^{-}}$ iNOS. The APBS-calculated electrostatic potential maps are projected on the surface of the Clobes of the solution structure of the CaM-iNOS peptide complex (A) and solution structure of the $\mathrm{CaM}_{34}$-iNOS peptide complex (B). The hydrophobicity surface calculated in chimera, using the Kyte-Doolittle scale, projected onto the surface of the C-lobes of the solution structure of the CaM-iNOS peptide complex (C) and solution structure of the $\mathrm{CaM}_{34}$-iNOS peptide complex (D). The electrostatic potential maps and hydrophobicity surfaces are colored as in Fig. 4.

FIGURE 8. The solution structure of the $\mathrm{CaM}_{34}$-iNOS peptide (dark colors) and the crystal structure of the iNOS oxy-FMN-holoCaM complex (CaM in light colors, iNOS CaM binding and FMN domains in yellow) are aligned by superimposition of the backbone atoms of CaM and the iNOS CaM binding domain. The side chains of key residues of CaM that interact with iNOS' heme domains and the distance of their shifts are labeled. The color scheme is the same as Fig. 2. Calcium ions are shown as orange spheres and labeled. 